点接触式温度プローブによる固体熱 3 定数の测定法 （温度プローブの改良）

\title{
Measuring Method of Three Thermophysical Parameters of Solids by a Thermal Probe with Instantaneous Point Contact (Improvement of Thermal Probe)
}

\author{
高橋一郎*、佐藤健一** \\ Ichiro Takahashi, Ken-ichi Sato
}

\begin{abstract}
点接触式温度プローブによる熱 3 定数の测定法は温度プローブが一様温度に加熱できて、その感温 部を適当な接触圧で被測定物体表面八点接触させることを要する。これまでの温度プローブがその要 件をどの程度渶たし得るかを検討し、本報では熱電対温度プローブの改良と、それを格納するプロー ブホルダーを開発した。温度プローブの加熱方法に関しては、軸方向に生ずる温度分布が熱物性測定 にいかに影響するかを実測と理論解析によって調バた。また、適切な加熱量を検㣙するため、被測定 物体八の伝熱量とプローブ加熱量との関係を調バた。測定時の接触熱抵抗の影響度を理論解析した結 果、本測定法は適切な接触圧が付加できるため熱抵抗の影響を容易に軽減できる。
\end{abstract}

The measuring method of three thermophysical parameters (thermal conductivity, thermal diffusivity, and specific heat capacity) of solids by a thermal probe with instantaneous point contact has been developed. The thermal probe is required to be uniformly preheated for the measurement. A compact probe holder is also required, which makes it easy for the tip of the probe to touch on a testing surface with a suitable contact-pressure. In this paper, the influence of an initial temperature distribution in the thermal probe on the temperature-response is discussed from the experimental and analytical results. A heated region of the probe is clarified. Influence of thermal contact-resistance between the tip of the probe and the testing surface is analytically examined. This method can reduce the influence to a negligible small. The probe is improved under the necessary conditions, and then the probe holder that is adaptable and easy for anyone to handle is developed.

[Keywords: three thermophysical parameters, solids, point contact method, thermal probe ]

\section{1.はじめに}

近年、各種工業部材の熱伝導率、熱拉散率、比熱容量(本 研究ではこれらをまとめて熱 3 定数と呼ぶことにする) を現位置で同時測定できる力法[1,2]が開発され、その奏 用化が期待されている。この点接触式温度プローブによ る固体熱 3 定数の測定法では非定常温度応答から接触面 積(半径)と熱 3 定数が同時に求められるため、接触面積

* 山形大学工学部機械システム工学科、テ992-5180 米沢市 城南 4-3-16 Dept. of Mech.Systems Engng. Yamagata University, 4·3-16 Jonan, Yonezawa 992-8510

FAX:0238-26-3205, E-mail: it@yz.yamagata·u.ac.jp **山形大学大学院工学研究科機械システム工学専攻
が熱物性値を算出する上で影響を与えない。また、温度 プローブを加熱するる場合は、被测定物体に対し適当な温 度差をつければよく、正確な温度設定を要しないなどの 利点がある。これまでは測定原理と被測定物体に関する 測定要件、および適用籁囲などが検討されてきた $[1,2]$ 。 しかし、温度プローブへの要件については十分検郡され ていない。本報は、 K熟電対を用いた温度プローブを対 象として、温度プローブが满たすべき要件、すなわち温 度プローブの加熱位置と加熱量、被測定面とプローブ感 温部との接触熱抵抗軽减などについて、実験と理論解析 により検討したものである。その結果から、温度プロー ブを改良し、操作性の良いプローブホルダーを開発した。 


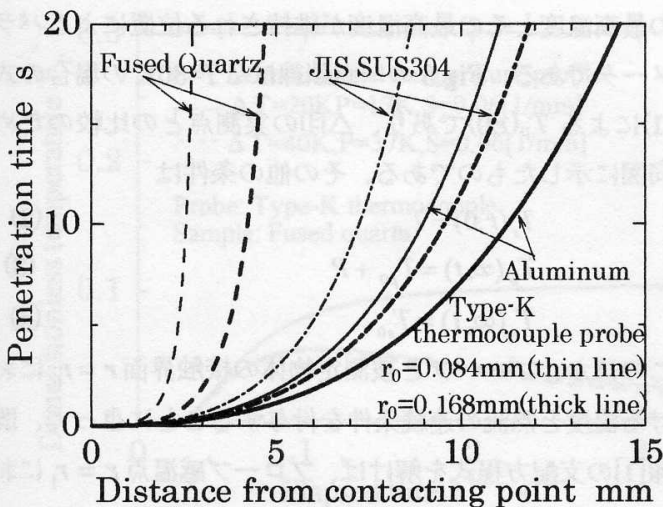

Fig.1 Thermal penetration area in the probe

\section{2. 熱電対温度プローブ側の温度浸透深さ}

測定直前に温度ブローブを室温より高い一定温度に保 つために、プローブを外部ヒーターで加熱している。し かし、一定発熱源が感温部近くに存在することによる温 度応答への影響をできるだけ避けなければならない。そ のためには测定時間内におけるプローブ側の温度浸透深 さ(初期温度より $0.1 \mathrm{~K}$ 以上の温度変化が現れる位置 $r)$ を考慮して、ヒーターを感温部からある程度離して取り 付けることが重要と考えられる。

プローブ側の温度変化の理論解 [1]から、温度浸透梁 さの時間変化を求めると Fig.1 が得られる。図の横軸は 接触点からの距離であり、縦軕は温度浸透に要する時間 である。この計算ではK熱電対を用いた温度プローブを 想定し、プローブ側の熱伝導率と熱浸透率值にクロメル の值を用いた。また、各被測定材側のそれらは文献值[3] によった。図中に示す接触半径 $r_{0}$ は実際の感温部寸法 から見積もった值である。Fig.1 から明らかなように、 接触半径の大きいほうが熱移動量が多く温度変化も深く 浸透する。被測定物体にもよるが、測定時間の $10 \mathrm{~s}$ 以内 に温度変化が見れるのは先端から $10 \mathrm{~mm}$ 程度までである。 したがって、外部ヒーター取り付け位置をプローブの先 端から $10 \mathrm{~mm}$ 程度離すことが必要である。

\section{3.プローブ側の初期温度分布}

\section{1 実測による温度分布}

$\S 4$ で詳述するが、測定時に被測定物体側へ流入する熱 量は微小であり、外部ヒーターによる加熱量はほとんど

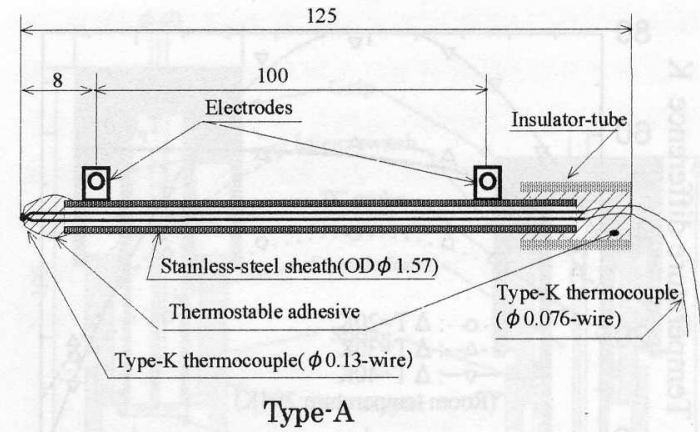

60

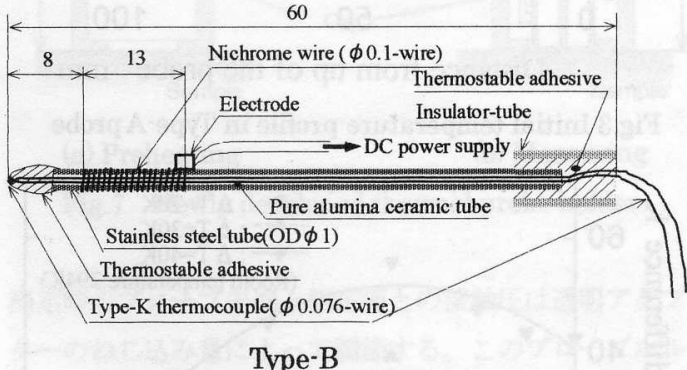

Type-B

Fig.2 Thermal probes

プローブホルダー側への熱損失となる。したがって、ヒ ーターの加熱量を少なくするには熱損失を低減する工夫 が必要である。一方、感温部から離れた位置にヒーター を取り付けた場合、プローブ温度は先端部で一様になら ず温度分布が生じる。そこで、この初期温度分布の存在 による温度応答への影響度を調べた。

Fig.2 に示す Type-A の温度プローブは既報[1]のそれ と同様の小法であるが、加熱部の軸方向温度分布が計測 し易いように作ったものである。先端から $8 \mathrm{~mm}$ 位置に 加熱部長さ $100 \mathrm{~mm}$ を設けた。全長 $125 \mathrm{~mm}$ のステンレスシ 一ス K 熱電対(線径 $0.13 \mathrm{~mm}$ )に線径が $0.076 \mathrm{~mm}$ の K熱電対 を接続している。この先端からプローブ表面の数筒所に 線径 $0.05 \mathrm{~mm}$ のK熱電対を取り付け、それを直径 $40 \mathrm{~mm}$ 、 長さ $130 \mathrm{~mm}$ 発泡スチロール製断熱ホルダーに格納した 状態で温度分布を測定した。感温部はその先端を被測定 面へ接触させるため、ホルダーからわずかに露出させて いる。この温度プローブでは、初期温度差 $\Delta T=30 \mathrm{~K}$ を 保つのに $0.61 \mathrm{~W}$ の加熱量を要し、Fig.3に示すような温 度分布が生じている。

Fig.2 の Type-B はK熱電対(線径 0.076 mm)をセラミッ クス細管に通し、それをステンレス管に入れて固定した ものである。加熱部長さは $13 \mathrm{~mm}$ で、樹脂製ホルダー( 3-2で詳还に入れて感温部先端をキャップでカバーした。 


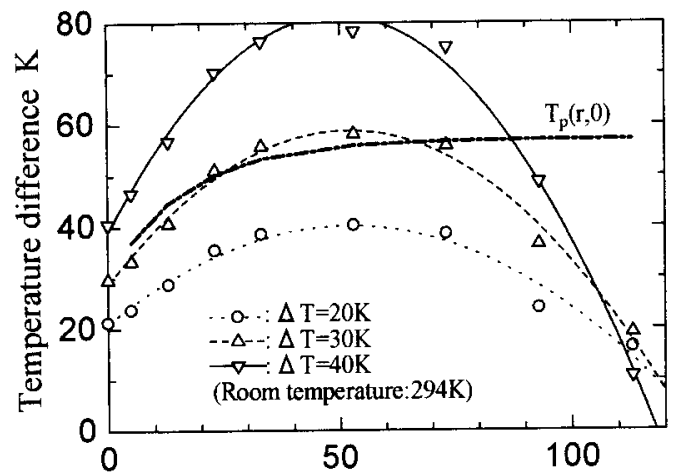

Distance from tip of the probe $\mathrm{mm}$

Fig.3 Initial temperature-profile in Type-A probe

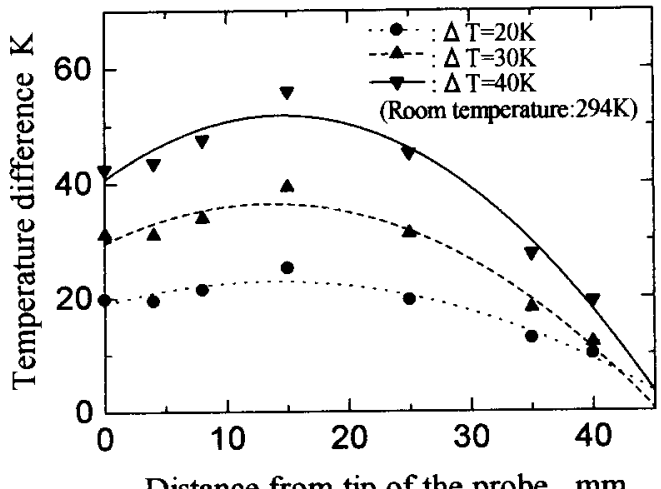

Distance from tip of the probe $\mathrm{mm}$

Fig.4 Initial temperature-profile in Type-B probe

Type-Bの軸方向温度分布はFig.4のようになった。先端 部における温度勾配が Type-A のそれより格段に小さく なっていることが分かり、初期温度美 $\Delta T=30 \mathrm{~K}$ を保つ ときの加熱量も $0.13 \mathrm{~W}$ と Type・Aに比心激减した。

\section{2 初期温度分布の温度応答への影響}

測定時、温度プローブ側に Fig.3に示すような初期温 度分布が存在する場合の温度応答を理論解析によって調 バた。プローブを他端が一定温度に加熱されたフィンと 考えれば、問題となる先端から加熱部における温度分布 は式(1)のような指数関数で表せる。すなうち、

$$
T_{p}(r, 0)=T_{p 0}+P\left[1-\exp \left\{-S\left(r-r_{1}\right)\right\}\right]
$$

既報[1]の測定理論では支配方程式が球座標系の伝熱 モデルによっているため、この温度分布も同じ座標系で 与える。したがって、トはプローブ先端からの距離を表 し、 $r_{1}$ は感温点位置である。 $P$ と $S$ はヒーター加熱部
の最高温度とその最高温度が維持される位置によるパラ メータである。Fig.3の一点鎖線は $\Delta T=30 \mathrm{~K}$ の場合の式 (1)による $T_{\mathrm{p}}(\boldsymbol{r}, 0)$ であり、 $\triangle$ 印の実測点との比較のため 同図に示したものである。その他の条件は

$$
\begin{aligned}
& T_{s}(r, 0)=T_{s 0} \\
& T_{p}(\infty, t)=T_{p 0}+P \\
& T_{s}(\infty, t)=T_{s 0}
\end{aligned}
$$

このほか、プローブと被測定物体の接触界面 $r=r_{0}$ にお ける温度と熱流の連続条件を付与することによって、既 報[1]の支配方程式を解けば、プローブ感温点 $r=r_{1}$ にお ける温度が次式のように得られる。すなわち、

$$
\begin{aligned}
T_{p}^{*}= & {\left[\frac{\beta}{\eta(\beta+1)}-\frac{P\left(S r_{0}+\beta\right) \exp \left\{-S\left(r_{0}-r_{1}\right)\right\}-P \beta}{\eta \Delta T(\beta+1)}\right] } \\
& \times \operatorname{erfc}\left(\frac{C}{\sqrt{t}}\right)+\left[\frac{\zeta-\beta}{\eta(\beta+1)(\zeta+1)}\right. \\
+ & \left.\frac{P\left\{S r_{0}(\zeta+1)-(\zeta-\beta)\right\} \exp \left\{-S\left(r_{0}-r_{1}\right)\right\}+P(\zeta-\beta)}{\eta \Delta T(\beta+1)(\zeta+1)}\right] \\
& \times \exp \left(X^{2}-\frac{C^{2}}{t}\right) \operatorname{erfc}(X)
\end{aligned}
$$

ここで、各パラメーターは、 $\Delta T=T_{p 0}-T_{s 0}$

$$
\begin{aligned}
& X=\frac{C}{\sqrt{t}}+\frac{(\beta+1)(\eta-1)}{2 C(\zeta+1)} \sqrt{t} \\
& \eta=\frac{r_{1}}{r_{0}}, \quad C=\frac{r_{1}-r_{0}}{2 \sqrt{a_{p}}}, \quad \beta=\frac{\lambda_{s}}{\lambda_{p}}, \quad \zeta=\frac{\xi_{s}}{\xi_{p}}
\end{aligned}
$$

この温度応答解において各[ ]内の第 2 項が初期温度 分们による影響度を表している。ところで、式(1)による プローブ初期温度分布では、感温点 $r=r_{1}$ での温度勾配 が $\partial T_{p} / \partial r=P S$ である。よって、この温度勾配を小さく するためにはPSを小さくしなければならない。

加熱部最大温度 $P$ は初期温度差 $\Delta T$ と連動して変化す る。しかし、無次元温度応答には $\Delta T$ による影響がほと んど現れない[2]。したがって、Pより $S$ のほうが温度応 答への影響が大きいと考えられる。Fig.3 の加熱部最高 温度位置から $S\left[\mathrm{~mm}^{-1}\right]$ を見積もると 0.06 となる。この条 件下の式(5)による理論温度応答は、溶骶石英の測定では Fig.5 となり、また純アルミニウムでは Fig.6 のようにな る。アルミニウムではこの初期温度分布によって温度応 答がわずかに低くなるだけであるが、溶融石英の場合は 


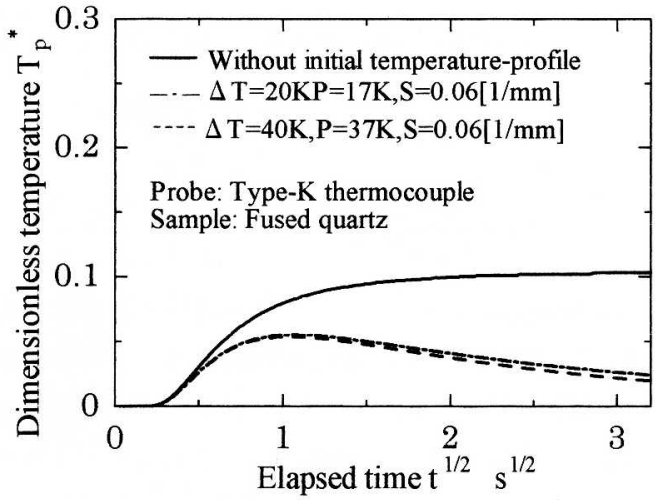

Fig.5 Theoretical temperature-responses

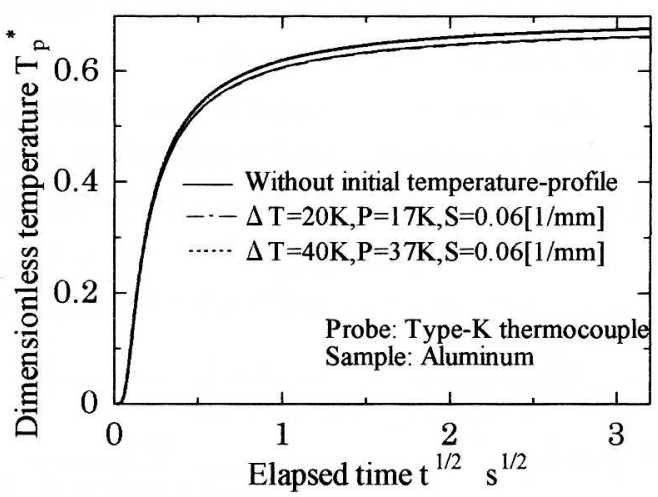

Fig.6 Theoretical temperature-responses

影響が顕著に現れている。つまり、熱浸透率が低い非金 属材ではプローブ温度が逆に上昇し、無次元温度 $T_{\mathrm{p}}$ *が 時間経過に伴い低下する現象が現れることが分かる。

Type-B 温度プローブでは先端の露出部分をキャップ で覆うことにより、Type-A に比べPは 3 分の 1 に、 $S$ 值は 5 分の 1 程度になった。この場合の計算結果は省略 するが、理論温度応答曲線では初期温度分布による影響 がほとんど無視できるオーダーになった。

プローブ先端をキャップで覆うようにしたプローブホ ルダーの断面構造を Fig.7 に示す。これにはマイクロス イッチが組み込まれており、プローブ感温部が被測定面 へ接触する時点と温度応答開始点とを対応づけることが できる。また、透明アダプターと被測定面との接触面に 熱電対を取り付けて被測定物体の初期温度 $T_{\mathrm{s} 0}$ を測定し ている。測定時に、このホルダーのグリップ部を手で押 し下げると、内側ホルダーが迫り出してキャップを押し のけ、感温部先端が被測定面一接触する仕組みである。

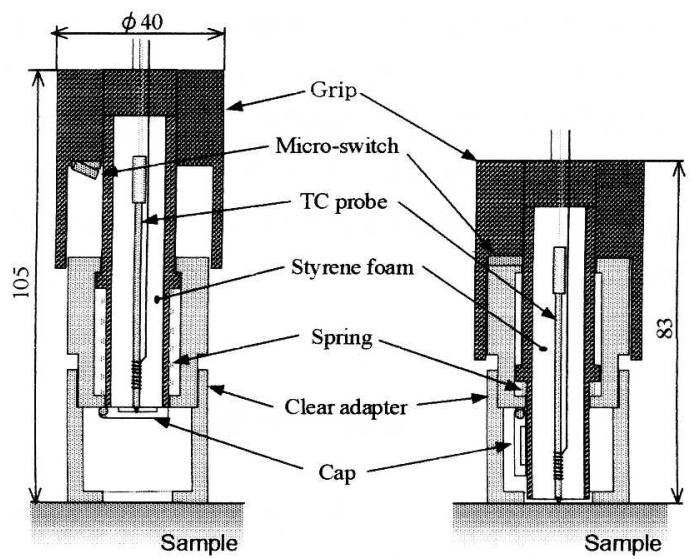

(a) Preheating

(b) Measuring

Fig.7 Newly developed thermal probe-holder

測定時のプローブ先端と測定面との接触圧は透明アダプ ターのねじ込み量によって調節する。このプローブホル ダーは樹脂製であり、小型軽量化を図ったものである。

\section{4. 接触界面における伝熱量}

接触面(接触半径 $r 0$ ) を通る伝熱量 $Q(t)$ は $r=r_{0}$ にお ける熱流束に半球面状伝熱面積 $2 \pi r 0^{2}$ を乗じて得られ る。その熱流束は

$$
q(t)=-\lambda_{s} \frac{\partial T_{s}}{\partial r}
$$

この $\partial T_{S} / \partial r$ は既報[2]に示された被測定物体側の非定常 温度の埋論解 $I_{\mathrm{s}}{ }^{*}(r, t)$ を用いて算出できる。一例として、 JS SUS304 試料に対しK熱電対プローブを $\Delta T=30 \mathrm{~K}$ 、 $r_{0}=0.168 \mathrm{~mm}$ で接触させた場合について Fig.8 に示す。 この図のように、Q(t)は接触直後に大きくなり約 $0.1 \mathrm{~s}$

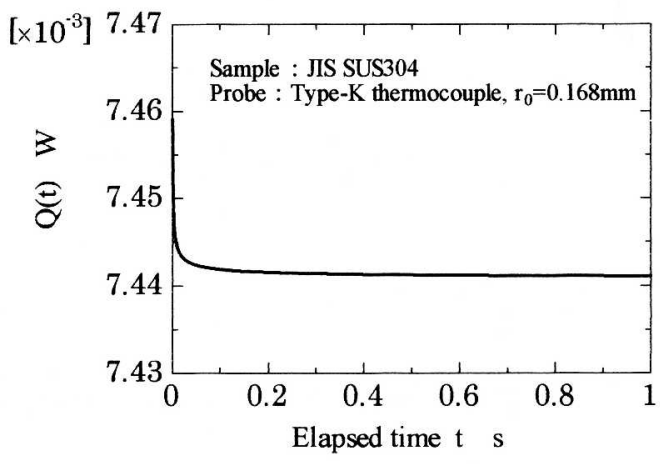

Fig. 8 Heat transfer rate from the probe to the sample 
経過後にほぼ一定堇となる。この傾向は被測定物の材質 によらず全ての場合に見られる。1 $\mathrm{s}$ 後のQ(むは ЛS

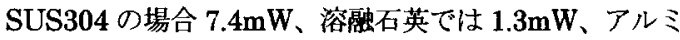
ニウムでは $12.6 \mathrm{~mW}$ であった。前述のように Type-B 温 度プローブでは初期温度差 $\Delta T=30 \mathrm{~K}$ を保つための加熱

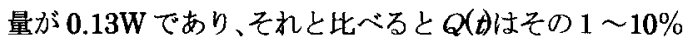
程度になっている。

\section{5. 接触熱抵抗の影響}

被測定面と温度プローブとの接触界面における接触熱 抵抗が温度応答へ影響する度合いを理論解析によって調 ぶる。

接触界面では温度の不連続があるとして、接触熱コン ダクタンス $h$ を以下のように定義する。ただし、 $\boldsymbol{b}$ は非 定常伝熱場でも一定であり、界面における熱流量は連続 と仮定する。

$$
r=r_{0} \text { で、 } \lambda_{p} \frac{\partial T_{P}}{\partial r}=-\lambda_{S} \frac{\partial T_{S}}{\partial r}=h\left(T_{P}-T_{S}\right)
$$

そして、測定理論[1]の初期条件及び境界条件と同じく、

$$
\begin{aligned}
& T_{P}(r, 0)=T_{P 0}, \quad T_{S}(r, 0)=T_{S 0} \\
& T_{p}(\infty, t)=T_{p 0}, \quad T_{s}(\infty, t)=T_{s 0}
\end{aligned}
$$

以上の条件下で、プーブ感温点 $\left(r=r_{1}\right)$ にお计る温度 応答の理論解を求めると次式を得る。

$$
\begin{aligned}
T_{P}^{*}= & \frac{C_{6}}{\eta C_{2}}\left\{\operatorname{erfc}\left(\frac{C}{\sqrt{t}}\right)-\exp \left(C_{1}^{2}-\frac{C^{2}}{t}\right) \operatorname{erfc}\left(C_{1}\right)\right\} \\
& +\frac{C_{7}}{\eta C_{4}}\left\{\operatorname{erfc}\left(\frac{C}{\sqrt{t}}\right)-\exp \left(C_{3}^{2}-\frac{C^{2}}{t}\right) \operatorname{erfc}\left(C_{3}\right)\right\}
\end{aligned}
$$

ここで、各パラメータは、

$$
\begin{aligned}
C_{1} & =\frac{C}{\sqrt{t}}+\frac{C_{2} \sqrt{a_{p} t}}{C_{5}}, C_{3}=\frac{C}{\sqrt{t}}+C_{4} \sqrt{a_{p} t} \\
C_{2} & =\frac{r_{0}}{2}[\zeta(\alpha+1)+\alpha \beta+1 \\
& \left.-\sqrt{\{\zeta(\alpha+1)+\alpha \beta+1\}^{2}-4 \alpha \zeta\{\beta(\alpha+1)+1\}}\right] \\
C_{4} & =\frac{r_{0}}{2 C_{5}}[\zeta(\alpha+1)+\alpha \beta+1
\end{aligned}
$$

$$
\begin{aligned}
& \left.+\sqrt{\{\zeta(\alpha+1)+\alpha \beta+1\}^{2}-4 \alpha \zeta\{\beta(\alpha+1)+1\}}\right] \\
& C_{5}=\zeta \alpha r_{0}{ }^{2}, \quad C_{6}=\frac{r_{0} \zeta C_{2}-\beta C_{5}}{C_{2}-C_{4} C_{5}} \\
& C_{7}=\frac{\beta-\zeta C_{4} r_{0}}{C_{2}-C_{4} C_{5}}, \quad C=\frac{r_{1}-r_{0}}{2 \sqrt{a_{s}}}, \quad \alpha=\frac{\lambda_{5}}{h r_{0}}
\end{aligned}
$$

この無次元パラメータ $\alpha$ が接触熱抵抗の影響度を決定 づける。被測定物体を JS SUS304 とし、プローブ側の 熱伝導率と熱浸透率にクロメルの值を与えた場合、Fig.9

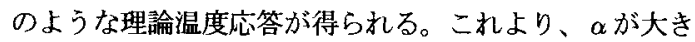
くなるほど温度応答が遅れ、 $T_{\mathrm{P}}^{*}$ *が小さくなることがわ かる。

接触半径が $r_{0}=0.168$ 組のK熱電対で $\alpha=7.5$ の場合は $h=10^{4} \mathrm{~W} /\left(\mathrm{m}^{2} \mathrm{~K}\right)$ になる。 $h$ 泣表面粗さにもよるが、この 值は通常の金属问士の平面接触界面において $10 \mathrm{MPa}$ 程 度の接触圧をかけた場合に相当する[4]。本測定では接触 面䅡が微小であるため、プローブへ $1 \mathrm{~N}$ 程度の荷重をか けても接触圧が $10 \mathrm{MPa}$ 以上となる。したがって、 $\alpha$ が 7.5 より小さくなるように接触させることは容易である。

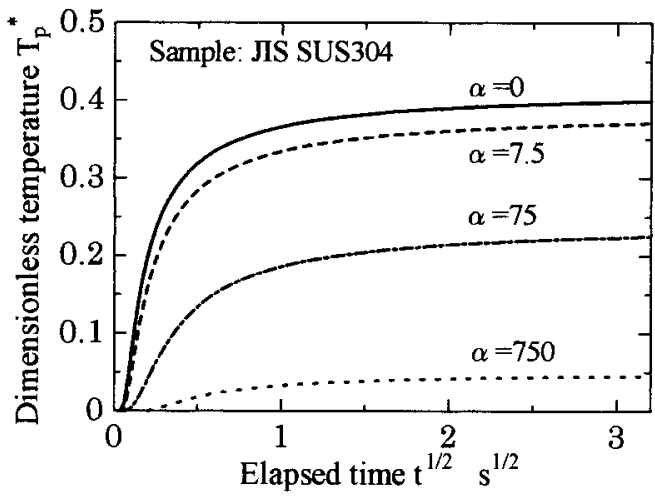

Fig.9 Influence of thermal contact-resistance upon temperature response

\section{6 . 装置構成}

本測定法の尒装置構成を Fig.10に示す。これらは小型 軽量であり、擭帯が容易で操作も簡単である。改良した 温度プローブを用いて金属及び非金属材料の常温におけ る温度応答を测定した結果を Fig.11 に示寸。これらは、 各 5 囘の测定值を重和書きしたものであり、これらの温 度伈答曲線加熱 3 定数(熱伝導率、熱拉散率、比熱容量) を算出した結果は再現性が約 $10 \%$ 程度に収まっている。 


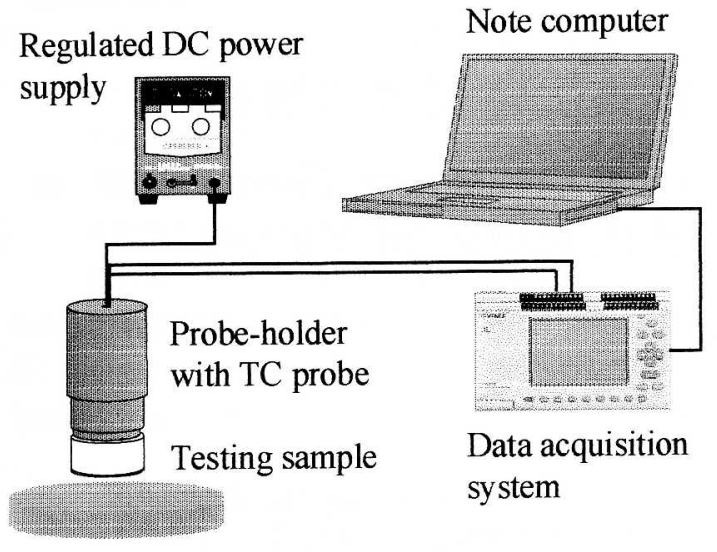

Fig.10 Measuring system of this method

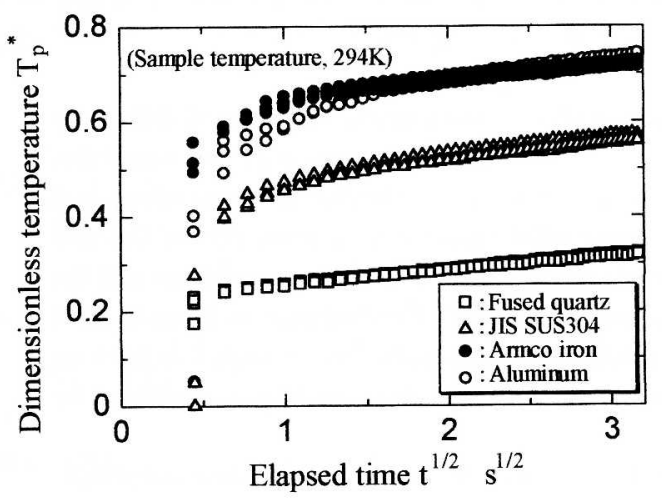

Fig.11 Measured temperature-responses

\section{7.おわりに}

点接触式温度プローブによる固体熱 3 定数の测定法に おいて、温度プローブに対する諸要件を検討した。その 結果を基にして温度プローブを改良し、操作性の良いプ ローブホルダーを開発した。得られた結果をまとめると 次のようになる。

（1）プローブに外部ヒーターを取り付ける場合、温度プ ローブ側の温度浸透深さを考慮すると、先端から $10 \mathrm{~mm}$ 程度㕍すことが必要である。

(2) 温度プローブに存在する初期温度分布の影響を軽減 する工夫が必要である。それには、被測定物体と接触す る直前までプローブ感温部を露山しないようにキャップ をすることが効果的である。
（3）金属試料の場合、温度プローブ先端と被測定面との 接触熱コンダクタンスは $h=10^{4} \mathrm{~W} /\left(\mathrm{m}^{2} \mathrm{~K}\right)$ 以上を必要と する。この hは通常 $10 \mathrm{MPa}$ 程度の接触圧下で実現でき る大きさであるが、本測定法では接触面積が微小である ことから、この条件を容易に満たすことができる。

\section{[顔辞]}

本研究は米沢電線(株)の研究助成を受けて遂行された ことを記し謝意を表します。また、実験に協力された本 学大学院学生、熊野和浩君に感謝致します。

\section{NOMENCLATURE}

a : thermal diffusivity, $\mathrm{mm}^{2} \cdot \mathrm{s}^{-1}$

C, $C_{1} \sim C_{7}:$ constant

erfc : complementary error-function,

$$
\operatorname{erfc}(x)=\frac{2}{\sqrt{\pi}} \int_{x}^{\infty} e^{-u^{2}} d u
$$

$h \quad:$ thermal contact-conductance, $\mathrm{W} \cdot \mathrm{m}^{-2} \cdot \mathrm{K}^{-1}$

$P \quad:$ parameter defined in Eq.(1), $\mathrm{K}$

$Q(t) \quad$ : heat transfer-rate at $r=n$

$r \quad$ : radial distance

$n \quad$ : radius of hemispherical contacting surface, mm

$n_{1}$ : position of temperature sensing point, $\mathrm{mm}$

$S \quad$ : parameter defined in Eq.(1), $\mathbf{m m}^{-1}$

$T \quad$ : temperature, $\mathrm{K}$

$T_{\mathrm{p}}{ }^{*}$ : dimensionless temperature,

$$
=\left(T_{p}-T_{p 0}\right) /\left(T_{s 0}-T_{p 0}\right)
$$

$\Delta T$ : initial temperature-difference, $=T_{p 0}-T_{s 0}$

$t \quad$ : time, s

$\alpha \quad:$ dimensionless parameter, $=\lambda_{\mathrm{p}} /(\boldsymbol{h} \cdot \mathbf{r})$

$\beta \quad$ : dimensionless parameter, $=\lambda_{\mathrm{s}} / \lambda_{\mathrm{p}}$

$\zeta \quad:$ dimensionless parameter, $=\xi_{\mathrm{s}} / \xi_{\mathrm{p}}$

$\eta \quad:$ dimensionless parameter, $=r_{1} / r_{0}$

$\lambda \quad$ : thermal conductivity, $\mathrm{W} \cdot \mathrm{m}^{-1} \cdot \mathrm{K}^{-1}$

$\xi \quad:$ thermal effusivity, $\mathrm{kJ} \cdot \mathrm{m}^{-2} \cdot \mathrm{s}^{-1 / 2} \cdot \mathrm{K}^{-1}$

Subscript

s : values of testing sample

$\mathrm{p} \quad$ : values of thermal probe

\section{参考文献}

[1] 高橋一郎、榎森正晃 ; 熱物性、13(1999),246-251.

[2] 高橋一郎、榎森正晃; 熱物性、13(1999),252-257.

[3] 日本機械学会編; 「伝熱工学資料」(改訂第 4 版) (養賢堂、1996).

[4] M.R.Sridhar,M.M.Yovanovich ; Trans.ASME, J.Heat Transf.,118(1996),3-9.

[Received May 10, 2002, Accepted Sept. 19, 2002] 